of M. Charcot, especially Bucquet, in which the anæsthesia and contraction were modified by the administration of gold.

It appeared proved, therefore, to the members of the Commission, that the internal treatment indicated for each of the patients by her external metallic aptitude had given the results announced by Dr. Burq.

This does not imply that a chronic diathesis was cured by a treatment of three months; but only that the treatment indicated by metalloscopic experiment appeared to modify, so long as it was continued, the dia. thetic manifestations, and conducted the patients towards a state of health.

These patients, however, remained subject to their diathesis; and when they appeared cured, remained apt to the external application of the metal, which now, when applied to the forearm or other part of the body, produced anæsthesia and relapsing anæsthesia. This relapsing anæsthesia became complete and general in all the cases, extending symmetrically to the four limbs ; invading the head, trunk, and general senses. This generalisation of anæsthesia was complete in from twenty to thirty-one minutes; if then the metal plaque were taken away, normal sensibility reappeared in all parts in the inverse order of the invasion of the anæsthesia. Some of the same set of phenomena were observed in respect to feeble electric currents from one element (Trouvé). This relapsing anæsthesia we have called, equally, metallic or post-metallic anæsthesia. It is valuable as showing the non-cure of the patients. Dr. R. Vigouroux demonstrated to us that, not only metals or continuous currents, but that also platinum-plates, charged with prolonged electricity, could bring about this relapsing anæsthesia ; also a single electrode of an isolated pile, that is to say, a rigorously unipolar application.

In this connection, Dr. Vigouroux studied the phenomena already mentioned, that metallic plates composed of two superposed metals did not always give results identical with those of uni-metallic plates. It was now ascertained that æsthetic or relapsing anæsthetic phenomena ceased to be produced when a plate of gold was superposed on a plate of silver or of copper. Further, other experiments taught us that the æsthesia or anæsthesia produced by a plate of gold was rendered persistent as soon as a plate of another metal was superposed upon the plate of gold. By this process, the phenomenon produced was fixed and prolonged so long as the superpo-ition of plaques lasted. To obtain these results, M. Vigouroux found that a plate of neutral metal (i. e., one to which the patient was not sensitive) needed to be superposed upon the active plate. This fixation of phenomena he thought probably due to a physical action of one metal on the other.

Another physiological observation led to another set of experiments It was that the peripheral modifications of sensibility described could only be the consequence of a peripheral action transmitted to the cerebro-spinal centre and reflected from the nerve-centres to the periphery. It was probable, therefore, that if by any proceeding the transmission of the peripheral impression towards the centre were arrested, the appreciable modifications of sensibility could not be produced. A neuiral plaque was, therefore, applied to the arm on the cardiac side of an active plaque in several cases. The result in every case was, that there was no modification of the peripheral sensibility Placed on the distal side of the active plaque, however, the neutral plaque did not in any way interfere with its action.

Guided by the like interpretation of the action of the centres, we placed on the left arm of a patient a bracelet of gold pieces (active metal), and on the right arm a bracelet of silver (neutral metal to the patient in question). No modification of sensibility was produced. The silver bracelet being removed, relapsing anæsthesia commenced in the left arm, and soon invaded the whole body. It is permissible, then, to suppose that, in this experiment, the silver had on the nerve centres an action which had neutralised that of the gold. Perhaps all the neutral metals have not an identical action in this respect, since a coppered gold bracelet substituted for the silver bracelet did not prevent the production of a relapsing hemianasthesia under the influence of the gold bracelet worn on the left arm.

\section{TWO CASES OF HYSTERO-EPILEPSY.} BY THOMAS INGLIS, F.R.C.P.Edin.,

Senior Assistant-Physician to the Royal Edinburgh Asylum; etc.

Hystero-Epileptic Fits. with Unilateral Convulsions; Somnambulistic Phenomena, Hemiplegia, Hemianasthesia, "Crucifiement".-The case of a man was recently tried, at the High Court of Justiciary in Edinburgh, for the murder of his child while he was in the somnambulistic state, which has excited considerable discussion among medicopsychologists as to whether such somnambulists should not be treated as persons of unsound mind.
There being no doubt that the deed was committed while the accused was in a state of sleep and unconscious of his acts, and therefore irresponsible, the jury accordingly returned a verdict of "not guilty"; and the judge stated that arrangements had been made with the prisoner and his friends to prevent a repetition of such a disaster. The arrangements were that the prisoner should use means to cure himself, and in future sleep alone. Such arrangements cannot be regarded as satis factory.

This somnambulist, labouring under the delusion that his child was a wild beast, killed it by dashing it on the wall, and was, without question, for the time, a person of unsound mind and dangerous to himself and others. An epileptic, committing a similar act, would doubtless have been put under care and treatment at once. It appears that almost all the relatives of the prisoner, for three generations past, have been tainted with epilepsy, and that the child he killed was sub ject to epileptiform convulsions. It is more than probable that the accused was labouring under the "epileptic sleep condition" which has been described by Westphal, Fischer, and others. In the present state of the law, the two following cases of insane hystero-epileptics, with somnambulistic phenomena, are not devoid of interest.

CASE I.--M. M., a girl aged I7, was admitted to the Royal Edin burgh Asylum on July 18th, 1878. After a short access of excitement, she had attempted suicide by precipitation from a fourth-storey window, but was arrested before accomplishing her purpose. She was then conveyed to a police-office, and sent from it to the asylum, where she was found to be in an unconscious state. After lying in a trance-like condition for eighteen hours, she regained consciousness. She was then perfectly collected and rational. No hereditary predisposition to insanity or other neurosis was admitted; but she had suffered from chlorosis, and was hysterical and of a nervous temperament. This was her first attack. Two days after admission, she was noticed to fall asleep while eating her dinner, and in the act of conveying food to her mouth ; and afterwards, when engaged washing clothes, she was found standing beside a tub in a state of profound sleep. She could not be aroused by shaking her violently, holding strong ammonia to her nose, or by pricking her with needles. Besides these attacks, she often walked about in this sleep condition with open eyes. On one occasion she fell down, but was not convulsed. She tried to resist the sleep coming on, but could not.

The patient was a girl of ordinary intelligence, and of a timid sensitive disposition. She was very anxious to be cured of these attacks. The morbid craving for sympathy, typical of "fashionable hysteria", was quite absent in this case. At night she slept, but complained of horrible dreams, and talked a great deal during her sleep.

A new phase of the disease now manifested itself. The patient said she felt a "painful rush" in the left iliac region (ovarian aura), and a feeling of distension of the abdomen. The face became pale, and she lost consciousness. Slight clonic convulsions of the left side of the face, left arm, and leg, then took place; while the right side was in a state of tetanic rigidity and contracture. Reflex action and common sensation on both sides were abolished during the attack. The pupils dilated, and were insensible to light. The attack could not be distinguished from an ordinary epileptic one with unilateral convulsions, foaming at the mouth, etc. Slight confusion of ideas and vertigo suc ceeded the attacks, but no stupor; and, if the invasion was slight, consciousness was regained suddenly. The pulse was 120 ; the temperature $99 \mathrm{deg}$. Fahr. These attacks became intensified in severity, and were succeeded by a transient left hemiplegia; its duration varying, according to the intensity of the paroxysm, from a few hours to one or two days. The paralysed leg was dragged straight forwards like an inert appendage, as occurs in hysterical paralysis. Left hemianæsthesia was complained of, and became complete at times. At rarer intervals, while the right side was hyperæsthetic, the left leg was numb and cold ; the left arm felt hot to the touch, and the palm of the hand perspired freely. Achromatopsia existed in a minor degree, and the sense of smell was impaired on the left side. Hearing and taste were normal. The urine was normal. The mucous membranes of the nose and eye of the left side were anxsthetic, while the tympanites present was probably due to a transient paralysis of the muscular coats of the intestines. In addition, she had hysterical attacks, in which consciousness was not entirely suspended, attended with violent contortions and hysterical contractions. She cried out frequently when they occurred, but never during the epileptiform attacks. The position of the cross (attitude de crucifiement) was occasionally assumed after such invasions. No ecstacy or delirium followed. The patient was not actuated by any exaggerated religious sentiments or desire for attention.

CASE II.-C. S., female, aged 18 , was subject to amenorrhœa. The insanity was brought on suddenly by a fright on hearing of her father's death, when she became excited, and developed the delusion that he was 
not dead, and hallucinations of sight, as that she saw him in the room, when he had been buried some days. She became very suicidal, and was sent to the asylum. The delusions and hallucinations rapidly passed off, but were replaced by hysteria and incomplete epilepsy. The features of her case resemble so much those of the previous one that it is unnecessary to repeat them here. The somnambulism was not so marked in it, but the hysterical and epileptiform phenomena were more exaggerated than in the other one. Her attacks were most frequent and severe at the menstrual periods, and were sometimes ushered in by sickness and vomiting. She was also aphasic for some time after the attacks.

An interesting experiment was made regarding the hemianæsthesia Over the left anæsthetic arm a mustard-blister leaf was tied, and removed some hours afterwards, when the whole arm was found to be hyperæsthetic : while the right arm, which was previously extremely sensitive, had become almost completely anæsthetic. This transfer of sensibility, or " phenomenon of transfer", as it is called by Westphal, only lasted a few hours. The paralysis was benefited by the use of electricity ; but the relief was only temporary, and it returned after the next epileptiform attack.

As regards the treatment, ovarian pressure in the case of M. M. does not appear to have any effect in shortening the paroxysms, but it arrested at once the hysterical attacks of C. S., but did not influence the epileptiform seizures. Nitrate of amyl at once arrests the convulsions, but, when its administration is suspended, they recur, and the attack is only protracted. Metalloscopy has not yet been fully tried, though Westphal has recorded several cases, in which it has been used with success, in the Berliner Klinisch. Wochenschrift (No. 30, 1878). Considerable benefit has been got from the use of the monobromide of camphor. Aloes and iron, to restore the catamenial discharge, were found useful ; and, when the latter is thoroughly established, a favourable termination to the case, as regards its severer features, may be looked for.

\section{CASE OF AN DISTRIBUTION.}

By J. DRESCHFELD, M.D., M.R.C.P. Assistant.Physician, Manchester Royal Infirmary; Lecturer on Pathology,
Owens College.

THस following case is of interest chiefly on account of its distribution, while in its character it bears a close resemblance to the anæesthesia observed in hystero-epilepsy.

Ellen C., aged 28, came to the out-patient room, Manchester Infirmary, on July 3 rd, 1878 , complaining of numbness in her right leg and left side of trunk, from which she had been suffering for more than a month.

The following notes were then taken by Mr. James Wood, one of my clinical clerks.

Previous History. - The patient had always enjoyed good health, and had never suffered from convulsions or other nervous symptoms; had been married for twelve months, and was confined of her first child on May 14th, 1878. During the whole time of pregnancy, she suffered but little; the labour, however, was a very tedious one; the patient suffered from labour-pains for more than four days, and had eventually to be delivered by instruments. Two days after confinement, she got out of bed, when she fainted, and for four days afterwards she remained in an unconscious state. She had no fits during the time, but rambled very much. As soon as she regained consciousness, she was able to get about ; but suffered from giddiness and headache. She noticed also, at the same time, numbness of her left breast. She could not tell whether the "baby was suckling the left breast unless she looked". She noticed the numbness in her right leg also at the same time. Her appetite was but indifferent, and she suffered slightly from hæmorrhoids. The symptoms not abating, she eventually came to seek relief at the Infirmary.

Present Condition. - The patient was of middle stature, healthy-looking, and of a ruddy complexion. The examination of the organs of the chest and abdomen revealed nothing but normal relations. There was no disturbance of either motion or nutrition, and the abnormal phenomena which were observed involved the sensory sphere exclusively. A careful examination elicited the following interesting symptoms.

Special Sense Oroans: Vision normal on both sides; the fundus of both eyes normal; no achromatopsia. Hearing: Complete deafness on the left side; hearing on the right side normal. Smell: Complete absence of smell on the left side; smell on the right side normal. Taste: Normal on both sides. No anæsthesia of either side of face and neck. Trunk: Anæsthesia of the left side. The anæsthetic portion was bounded by the middle line, both in front and behind. Its upper margin was formed by a line passing horizontally round the left side, just above the third rib, and passing under the axilla to the middle line behind, while its lower border was bounded by a line commencing just above the pubes, and passing at first along Poupart's ligament and then horizontally round the left side (about one inch below the crest of the ilium) to the lowest part of the sacrum. Upper Extremities: Both were perfectly normal as regards sensibility and mobility. Lower Extremities: The left leg and thigh were perfectly normal both as regards motion and sensation; the right leg and thigh could be moved with perfect freedom, but were completely anæsthetic. The upper limit of the anæsthetic right lower extremity coincided exactly with the lower limit of the anæsthetic left half of the trunk, i.e., just where the patient began to feel tactile impressions on the right side there the anrsthesia on the left side commenced. There was no ovarian hyperæsthesia. Examining the character of the anæsthesia more minutely, the following points were made out.

I. Total loss of perception of tactile impressions in all the anæsthetic parts.

2. Analgesia of these parts. The right calf was transfixed by a large dissecting needle without the patient evincing the least sensation; the same needle was passed deeply into the left mamma and other parts of the left half of the trunk with the same result. The points where the needle was inserted bled freely.

3. Loss of muscular sense. The patient, with her eyes shut, had no knowledge of the relative position of the anæsthetic leg. She was told to sit down and shut her eyes, and, on now moving the right leg, she was still under the impression that the right foot touched the floor.

4. Loss of sense for temperatures ; neither cold nor heat was perceived by any of the anæsthetic parts. The sense for weights was not examined into.

On July 8th, the patient presented herself again, and her condition had undergone no change, and we now determined the behaviour of the anæsthetic parts to the electric current. On applying an induction current of moderate strength to the anæsthetic leg (one pole being placed in contact with the lumbar part of the spine, and the other with the calf of the right leg), the patient felt the current distinctly, and, on now increasing the strength of the current, the patient complained of a painful sensation, and distinct contraction was visible. We then tested the sensibility of a point in the left calf symmetrically situated with that on the right calf, to which the electrophone had been applied ; but the sensibility had remained the same, and, therefore, no transfer thad taken place. To the galvanic current the anæsthetic parts responded, though less distinctly than on the sound side.

Progress. - July roth. Ever since the application of the faradic current, the patient felt a slight return of sensibility, not only in the right leg, but also in the left half of the trunk. There was, however, still a considerable amount of dysæsthesia. The faradic current was now regularly applied by Mr. J. Wood, but only to the right leg, and with very satisfactory results ; for, on August 15 th, it was noted that the anæsthesia and analgesia had entirely disappeared from the right leg and left half of the trunk. Hearing and smell were still somewhat impaired on the left side, though a considerable improvement had taken place here too.

Since then, the patient presented herself once more, and reported that she was quite cured. A close examination showed still a slight affection of the organs of hearing and smell on the left side. The patient experienced, however, so little discomfort from this, that she was unwilling to submit to further treatment.

Before concluding this brief sketch, it may be of interest to state that lactation was in no way interfered with, and that the left mamma yielded quite as much milk as the right.

REMARKS. - The case presents several peculiarities. I. The distribution of the anæsthesia is, as far as I can make out, unique. Briquet describes several cases of hysteria with alternating anæsthesia ; but, in all these cases, the whole of one side of the trunk and the opposite side of the face were so affected, and the same distribution has been observed in cases of anæsthesia dependent on organic lesions (Gazette Hebdom., 1878, Nos. I and 3). Again, I believe, in all cases of hysteroepilepsy described, the anæsthesia observed was distinctly unilateral, affecting the sense organs, the trunk, and the extremities of the same side. The integrity of the upper extremity of the face and neck, of vision, and of the sense of taste in this case is equally remarkable.

2. In its character the case very much resembles cases of hysteroepilepsy ; but here the absence of other hysterical symptoms, especially the absence of any hystero-epileptic attack, will again be remarked, unless we consider the attack of unconsciousness which took place soon after the confinement as a kind of trance or comatose condition, not unlike that observed in a case recently published by Vigoureux. (Pros. Médic., 1878, page 679.) The sudden seizure and the fact that 